\title{
Heterogeneous Iridium Oxide/Gold Nanocluster for Non-enzymatic Glucose Sensing and pH Probing
}

\author{
Qiuchen Dong, ${ }^{1 *}$ Xudong Wang, ${ }^{2}$ Haomin Liu, ${ }^{3}$ Heejeong Ryu, ${ }^{3}$ Jing Zhao, ${ }^{2}$ Baikun $\mathrm{Li}^{4}$ and Yu Lei ${ }^{1,3^{*}}$
}

In this work, heterogeneous gold-doped iridium oxide nanoclusters $\left(\mathrm{IrO}_{2}-\mathrm{Au} \mathrm{NCs}\right)$ that are both pH-sensitive and glucose-responsive were synthesized through electrospinning followed by high-temperature calcination. The as-prepared $\mathrm{IrO}_{2}-\mathrm{Au}$ NCs were systematically characterized using various advanced techniques including scanning electron microscopy, X-ray powder diffraction and Raman spectroscopy. They were then employed as the sensing element to fabricate a sensor for both non-enzymatic glucose sensing and solid-state $\mathrm{pH}$ monitoring. Sensing performance of the $\mathrm{IrO}_{2}-\mathrm{Au} \mathrm{NCs}$ based dual sensor toward $\mathrm{pH}$ and glucose was evaluated using various electrochemical techniques, including potentiometric, cyclic voltammetry and amperometric techniques. The results show that the as-prepared $\mathrm{IrO}_{2}-\mathrm{Au} \mathrm{NCs}_{\text {not }}$ only maintain accurate and reversible $\mathrm{pH}$ sensitivity derived from $\mathrm{IrO}_{2}$, but also demonstrate good electrocatalytic activity resulted from Au toward glucose oxidation in alkaline medium at a low applied potential with a sensitivity of $21.20 \mu \mathrm{A} \mathrm{mM}^{-1} \mathrm{~cm}^{-2}$, a limit of detection of $2.93 \mu \mathrm{M}(\mathrm{S} / \mathrm{N}=3)$ and a reasonable selectivity against various interferences. These features show that the as-prepared $\mathrm{IrO}_{2}-\mathrm{Au} \mathrm{NCs}$ hold great promise as a dual-functional sensing material for the development of a high-performance sensor for both solid-state $\mathrm{pH}$ and non-enzymatic glucose sensing.

Keywords: Iridium oxide-Au; Nanoclusters; Electrospinning; Non-enzymatic; Glucose detection; pH sensing; Dual sensor

Received 28 February 2019, Accepted 22 May 2019

DOI: $10.30919 / \mathrm{es} 8 \mathrm{~d} 512$

\section{Introduction}

In the past decades, both $\mathrm{pH}$ and glucose sensing technology have been separately and extensively studied due to their importance in probing the acidity/alkalinity of aqueous solutions and blood glucose level for diabetic patients, respectively. With respect to $\mathrm{pH}$ sensing, conventional glass-type $\mathrm{pH}$ electrode is the most widely used in laboratory environment; however, it suffers from the fragileness. Therefore, ionselective field effect transistor ${ }^{14}$ and optical $\mathrm{pH}$ sensors ${ }^{5}$ are developed to improve the durability of $\mathrm{pH}$ sensors. However, their wider applications are greatly limited by its high power consumption, high cost, and unsuitability for harsh environment applications. Therefore, solid-state $\mathrm{pH}$ sensors that measure the electromotive force difference between the sensing and reference electrodes have gradually attracted researchers' attention in $\mathrm{pH}$ sensing because of their ability for miniaturization, cost-effectiveness, as well as the long-term stability and durability. Up to date, a spectrum of $\mathrm{pH}$-responsive metal oxides have been extensively studied for $\mathrm{pH}$ detection, ${ }^{6-7}$ some of which hold great promise. In regard to glucose sensing, intermittent and continuous glucose monitoring is of paramount importance for diabetic patients to

\footnotetext{
Department of Biomedical Engineering, University of Connecticut, 191 Auditorium Rd, Storrs, CT, 06269-3222, USA

Department of Chemistry, University of Connecticut, $55 \mathrm{~N}$ Eagleville Rd, Storrs, CT, 06269-3060, USA

${ }^{3}$ Department of Chemical and Biomolecular Engineering, University of Connecticut, 191 Auditorium Rd, Storrs, CT, 06269-3222, USA

${ }^{4}$ Department of Civil and Environmental Engineering, University of Connecticut, 261 Glenbrook Rd, 06269-3037, USA

*E-mail: quichen.dong@uconn.edu; yu.lei@uconn.edu
}

track and manage their blood glucose level. Nowadays, glucose oxidase (GOx) and glucose dehydrogenase (GDH) based test strips dominate glucose sensor market. Although great success has been achieved using GOx and GDH, the intrinsic thermal and chemical sensitivity of enzyme stimulates the research community to pursuit more stable nonenzymatic catalysts in glucose detection. Consequently, non-enzymatic glucose sensors are developed as an alternative. Amongst various types of non-enzymatic glucose sensing materials, metal oxides stand out in the development of non-enzymatic glucose sensors because of their easy accessibility, low cost, and superior chemical/thermal stability. A range of metal oxides and their composite materials (e.g. $\mathrm{Co}_{3} \mathrm{O}_{4}{ }^{8-10}$ $\mathrm{Co}_{3} \mathrm{O}_{4} /$ graphene, ${ }^{11} \mathrm{NiO},{ }^{12}$ noble metal doped $\mathrm{NiO},{ }^{13} \mathrm{CuO},{ }^{1415} \mathrm{Cu}_{2} \mathrm{O}-\mathrm{TiO}_{2}{ }^{16}$ etc.) were exploited as innovative non-enzymatic glucose catalysts in glucose detection, respectively.

Although there are numerous reports about solid-state $\mathrm{pH}$ sensing or metal oxide based non-enzymatic glucose sensing, a majority of the techniques are developed based on the concept of "one sensor for one target". The development of dual sensors is heavily overlooked because of the lack of multi-functionality in a single sensing material. Therefore, a dual sensor, which can accomplish both non-enzymatic glucose sensing and solid-state $\mathrm{pH}$ sensing, still remains elusive. To accomplish dual sensor concept, novel functional sensing materials or current sensing materials with newly explored functions should be employed in the construction of sensors.

In our previous study, ${ }^{17}$ iridium oxide has been demonstrated with both good solid-state $\mathrm{pH}$ sensing and glucose sensing properties, while noble metals, especially $\mathrm{Au}^{18}$ and $\mathrm{Pt},{ }^{19}$ show good conductivity and glucose sensing property. To further improve the sensing performance of iridium oxide, in this study, gold is doped into iridium oxide during its preparation process. Compared to pristine iridium oxide, gold-doped iridium oxide nanostructured material is expected to not only possess 
$\mathrm{pH}$ sensing property inherited from iridium oxide, but also hold promise to lower the operating potential in glucose sensing which is attributed to gold.

The goal of this study aims at developing a dual functional electrochemical sensor for both glucose and $\mathrm{pH}$ sensing using a composite sensing material, which consists of $\mathrm{IrO}_{2}$ and $\mathrm{Au}$. Au-doped $\mathrm{IrO}_{2}$ nanoclusters $\left(\mathrm{IrO}_{2}-\mathrm{Au} \mathrm{NCs}\right)$ were prepared by electrospinning followed by a high temperature annealing process. The as-prepared $\mathrm{IrO}_{2}$-Au NCs was employed to modify glassy carbon electrode. Its $\mathrm{pH}$ and glucose sensing performance was systematically investigated using potentiometric, cyclic voltammetry and amperometric techniques.

\section{Experimental}

\subsection{Reagents}

Iridium (IV) tetrachloride $\left(\mathrm{IrCl}_{4}\right)$ was purchased from Alfa Aesar and used without further purification. Polyvinylpyrrolidone (PVP, $M W=1,300,000$ ) and Nafion 117 solution (purum, $\sim 20 \%$ in a mixture of lower aliphatic alcohols and water) were supplied from SigmaAldrich. Hydrogen tetrachloroaurate trihydrate $\left(\mathrm{HAuCl}_{4} \cdot 3 \mathrm{H}_{2} \mathrm{O}\right)$ Dimethylformamide (DMF), D-(+)-glucose, 4-acetominopheon, ascorbic acid, and uric acid, as well as ethanol were obtained from Acros Organics. All aqueous solutions were prepared with deionized water $(18.2 \mathrm{M} \Omega \mathrm{cm})$ generated by a Barnstead water system.

\subsection{Fabrication of $\mathrm{IrO}_{2}-\mathrm{Au}$ nanoclusters}

For preparation of $\mathrm{IrO}_{2}-\mathrm{Au}$ nanoclusters, $0.19 \mathrm{~g}$ iridium tetrachloride was dissolved in $4 \mathrm{~mL}$ of dimethylformamide (DMF) solution, followed by addition of $0.1 \mathrm{~g} \mathrm{HAuCl}_{4}$ and another $0.87 \mathrm{~g}$ PVP. The mixed solution was overnight stirred under magnetic stirring. The asprepared homogenous solution was then electrospun using 23-gauge needle with a flow rate of $0.3 \mathrm{~mL} / \mathrm{h}$ at an applied voltage of $20 \mathrm{kV}$ over an aluminum foil collector ( $15 \mathrm{~cm}$ to the tip of needle). Such precursor solution without the addition of $\mathrm{HAuCl}_{4}$ or $\mathrm{IrCl}_{4}$ was also prepared for control experiments. The $\mathrm{IrCl}_{4}-\mathrm{HAuCl}_{4} / \mathrm{PVP}$ and $\mathrm{IrCl}_{4} / \mathrm{PVP}$ nanofibers collected on the collector were then peeled off. After $3 \mathrm{~h}$ dehydration process at $80{ }^{\circ} \mathrm{C}$ in an oven, the as-prepared precursory $\mathrm{IrCl}_{4}$ $\mathrm{HAuCl}_{4} / \mathrm{PVP}$ or $\mathrm{IrCl}_{4} / \mathrm{PVP}$ nanofibers were calcined under ambient atmosphere at $900{ }^{\circ} \mathrm{C}$ for $3 \mathrm{~h}$ with a ramp-up speed at $2{ }^{\circ} \mathrm{C} / \mathrm{min}$. The furnace was then allowed to naturally cool down to room temperature and the annealed $\mathrm{IrO}_{2}$-Au NCs and $\mathrm{IrO}_{2} \mathrm{NCs}$ were collected.

\subsection{Preparation of $\mathrm{IrO}_{2}-\mathrm{Au} \mathrm{NCs}$ modified glassy carbon electrode}

Before modification of the surface, glassy carbon electrode (GCE, dia. $3 \mathrm{~mm}$ ) was polished with $1 \mu \mathrm{m}$ and $0.05 \mu \mathrm{m}$ alumina slurries sequentially, and then rinsed with DI water. Afterwards, the electrode was cleaned by ultra-sonic bath for $5 \mathrm{~min}$ in acetone, ethanol and DI water in sequence, and then dried at room temperature. The loading of $\mathrm{IrO}_{2}-\mathrm{Au} \mathrm{NCs}$ on the glassy carbon electrode was first optimized using cyclic voltammetry in $0.1 \mathrm{M} \mathrm{NaOH}$ and in $0.01 \mathrm{M}$ PBS buffer. 7 $\mathrm{mg} / \mathrm{mL}$ of $\mathrm{IrO}_{2}-\mathrm{Au} \mathrm{NCs}$ with a fixed loading volume of $8 \mu \mathrm{L}$ shows the best $\mathrm{CV}$ response, thus being used for subsequent experiments. To prepare $7 \mathrm{mg} / \mathrm{mL} \mathrm{IrO}_{2}-\mathrm{Au} \mathrm{NCs}$ suspension, $7 \mathrm{mg}$ of calcined $\mathrm{IrO}_{2}-\mathrm{Au}$ NCs sample was suspended in $1.0 \mathrm{ml}$ ethanol and then subject to 30 min of ultra-sonication. Afterwards, $8 \mu \mathrm{L} \mathrm{IrO}_{2}-\mathrm{Au} \mathrm{NCs/ethanol}$ suspension was drop-cast onto the pre-cleaned glassy carbon electrodes. After solvent evaporation, $5 \mu \mathrm{L}$ of Nafion solution ( $1 \mathrm{wt} \%$ in ethanol) was further drop-cast onto the top of $\mathrm{IrO}_{2}-\mathrm{Au} \mathrm{NCs}$ and dried in air to entrap the nanoclusters. The as-prepared electrode is denoted as $\mathrm{Nafion} / \mathrm{IrO}_{2}-\mathrm{Au} \mathrm{NCs} / \mathrm{GCE}$. Nafion-coated glassy carbon electrode (Nafion/GCE) was also prepared as a control electrode following the same procedure. Before use, each electrode was submerged into DI water for an appropriate time to allow Nafion membrane to swell. All experiments were repeated for at least 3 times to ensure the reproducibility.

\subsection{Apparatus and electrochemical measurements}

A JEOL 6335F field-emission scanning electron microscope (SEM) was used to examine the morphology and the size of the as-electrospun precursory nanofibers and $\mathrm{IrO}_{2}-\mathrm{Au}$ NCs. Transmission electron microscopic (TEM) images, high angle annular dark field-scanning transmission electron microscopic (HAADF-STEM) images, energy dispersive X-ray (EDX) elemental mapping data, and selected area electron diffraction (SAED) patterns were acquired using a Thermo Fisher Scientific -Talos microscope operated at an accelerating voltage of $200 \mathrm{kV}$. The X-ray powder diffraction patterns (XRD) were obtained with a Rigaku UltimaIV instrument with $\mathrm{Cu} \mathrm{K} \alpha$ radiation $(=0.154056$ $\mathrm{nm}$ ) operating at $40 \mathrm{kV}$ and $45 \mathrm{~mA}$ beam current. Raman spectra were recorded at ambient temperature on a Reinshaw Ramanscope MicroRaman with $514 \mathrm{~nm}$ wavelength lasers. Cyclic voltammetry (CV), amperometry and open circuit potential measurements were performed on a CHI 601C Electrochemical Workstation (CH Instruments, USA). All experiments were conducted using a standard three-electrode electrochemical cell, consisting of a working electrode (GCE, dia. 3 $\mathrm{mm}$ ), an $\mathrm{Ag} / \mathrm{AgCl}$ reference electrode, and a platinum counter electrode (dia. $3 \mathrm{~mm}$ ). For amperometric glucose detection, all signals were recorded after current decayed to a steady-state value and a stirrer was used to provide convective mixing. For $\mathrm{pH}$ sensing, the $\mathrm{pH}$-adjustable buffer was prepared using a recipe from a previous report. ${ }^{20}$ Briefly, $\mathrm{pH}$ 3.0-9.0 solutions were universal buffers containing $10 \mathrm{mM}$ potassium hydrogen phthalate, $10 \mathrm{mM}$ phosphate, and $10 \mathrm{mM}$ Tris, while $\mathrm{pH} 10.0$ and 13.0 solutions contained $50 \mathrm{mM}$ sodium carbonate and $10 \mathrm{mM}$ borax and $140 \mathrm{mM}$ of $\mathrm{NaCl}$. The $\mathrm{pH}$ adjustment was realized by addition of $1 \mathrm{M} \mathrm{HNO}_{3}$ or $1 \mathrm{M} \mathrm{NaOH}$.

\section{Results and discussion}

\subsection{Morphology and composition of $\mathrm{IrO}_{2}-\mathrm{Au} \mathrm{NCs}$}

Fig. 1A shows the typical morphology of the precursory $\mathrm{IrCl}_{4-}$ $\mathrm{HAuCl}_{4} / \mathrm{PVP}$ nanofibers. One can see that the precursory nanofibers possessed smooth surface and the diameter of the precursory nanofibers is $130 \pm 23 \mathrm{~nm}\left(\mathrm{IrCl}_{4} / \mathrm{HAuCl}_{4} / \mathrm{PVP}\right.$ nanofibers $)$. After degradation of PVP and decomposition of $\mathrm{IrCl}_{4}$ and $\mathrm{HAuCl}_{4}$ at high temperature, a nanocluster morphology was formed (Fig. 1B) due to the migration of iridium oxide and $\mathrm{Au}$ element.

The as-prepared nanoclusters in ethanol suspension were subjected to $30 \mathrm{~min}$ of ultrasonication before TEM characterization. TEM image (Fig. 2) also reveals that the $\mathrm{IrO}_{2}-\mathrm{Au}$ shows nanocluster structure, in good agreement with Fig. 1B. Furthermore, the element mapping of Ir, $\mathrm{Au}$, and $\mathrm{O}$ in Fig. 2 indicates that the element gold is uniformly distributed into the backbone of iridium and oxygen. The d-spacing values in Fig. 3B were measured to be $0.314 \mathrm{~nm}$ and $0.231 \mathrm{~nm}, 0.204$ $\mathrm{nm}$, which can be attributed to $\left(\begin{array}{lll}1 & 1 & 0\end{array}\right)$ planes of $\mathrm{IrO}_{2}$ and $\left(\begin{array}{lll}1 & 1 & 1\end{array}\right)$ and $(2$ 0 0) planes of elemental Au. The SAED patterns shown in Fig. 3C clearly display several rings, which can be indexed to the planes of (1 1

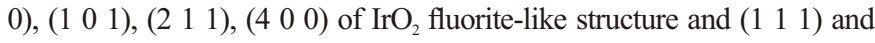
(2 2 ( 0 ) planes of elemental Au. These studies indicate that Au was successfully doped into $\mathrm{IrO}_{2}$.

In order to monitor the composition change of $\mathrm{IrCl}_{4} / \mathrm{HAuCl}_{4} / \mathrm{PVP}$ precursor before and after annealing process, Fourier-Transform Infrared spectroscopy (FT-IR) was applied to analyze the samples. One can see that the transmission bands associated with PVP at ca. $1640 \mathrm{~cm}^{-1}, 1420$ 

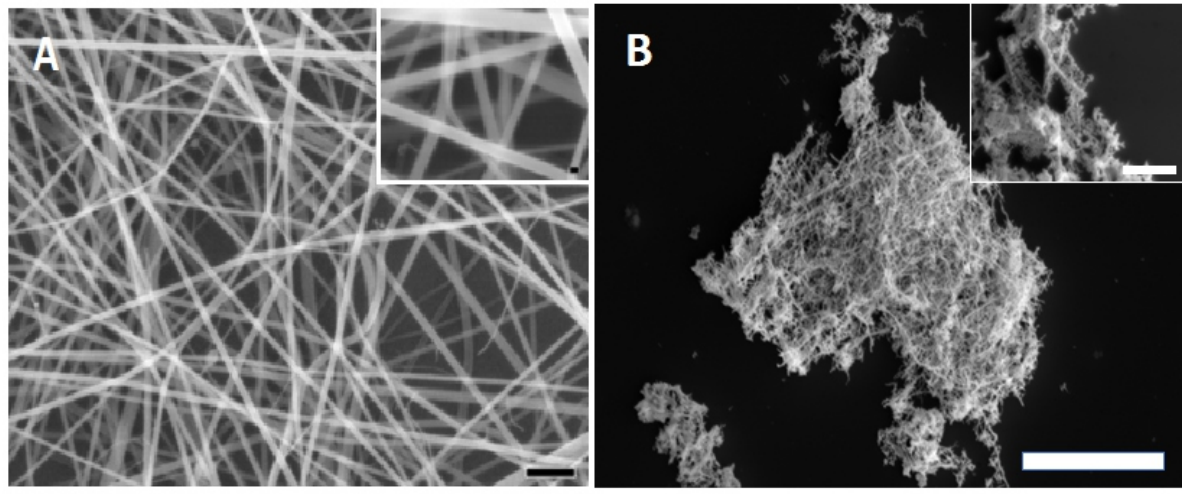

Fig. 1 (A) SEM image of $\mathrm{IrCl}_{4} / \mathrm{HAuCl}_{4} / \mathrm{PVP}$ nanofibers (Scale bar: $1 \mu \mathrm{m}$ and $100 \mathrm{~nm}$ for inset). (B) SEM image of annealed IrO $-\mathrm{Au}$ nanoclusters (Scale bar: $10 \mu \mathrm{m}$ and $2 \mu \mathrm{m}$ for inset).

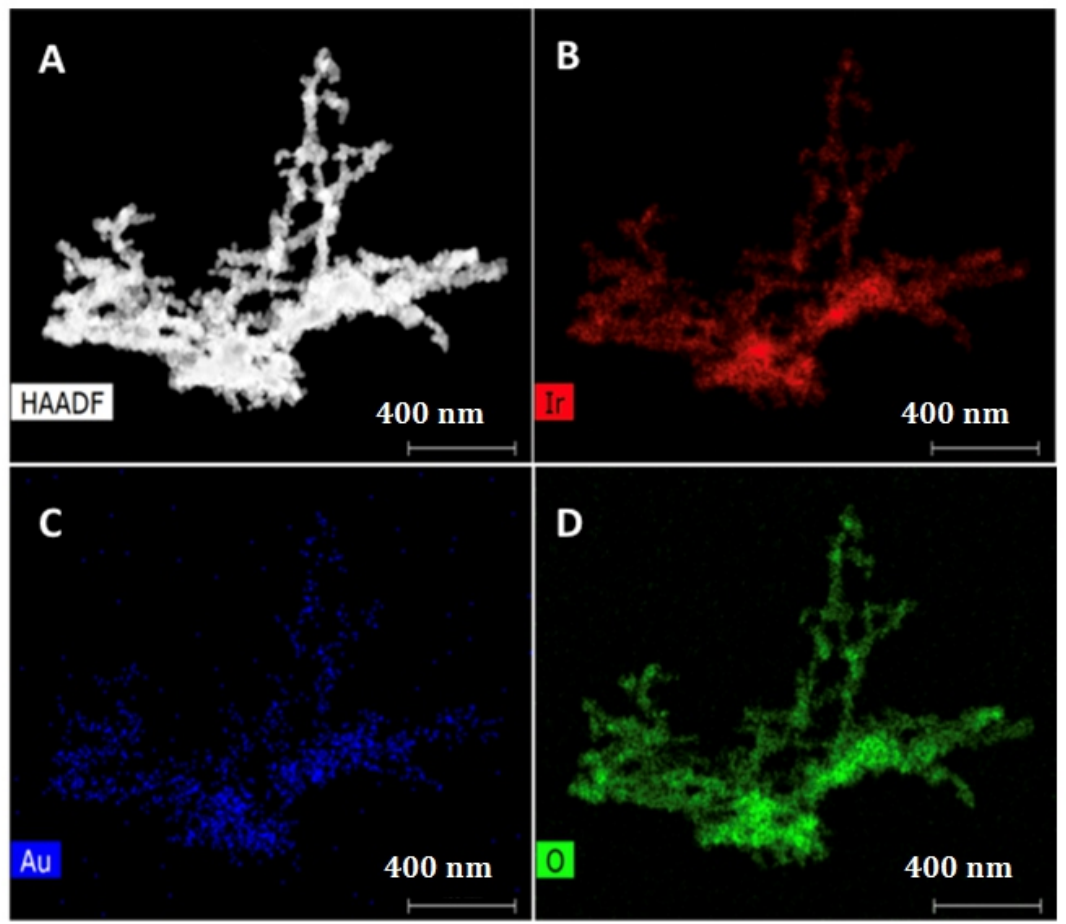

Fig. 2 TEM metal mapping to the gold-doped iridium oxide nanoclusters with HAADF (A), Ir mapping (B), Au mapping (C), and O mapping (D), respectively.
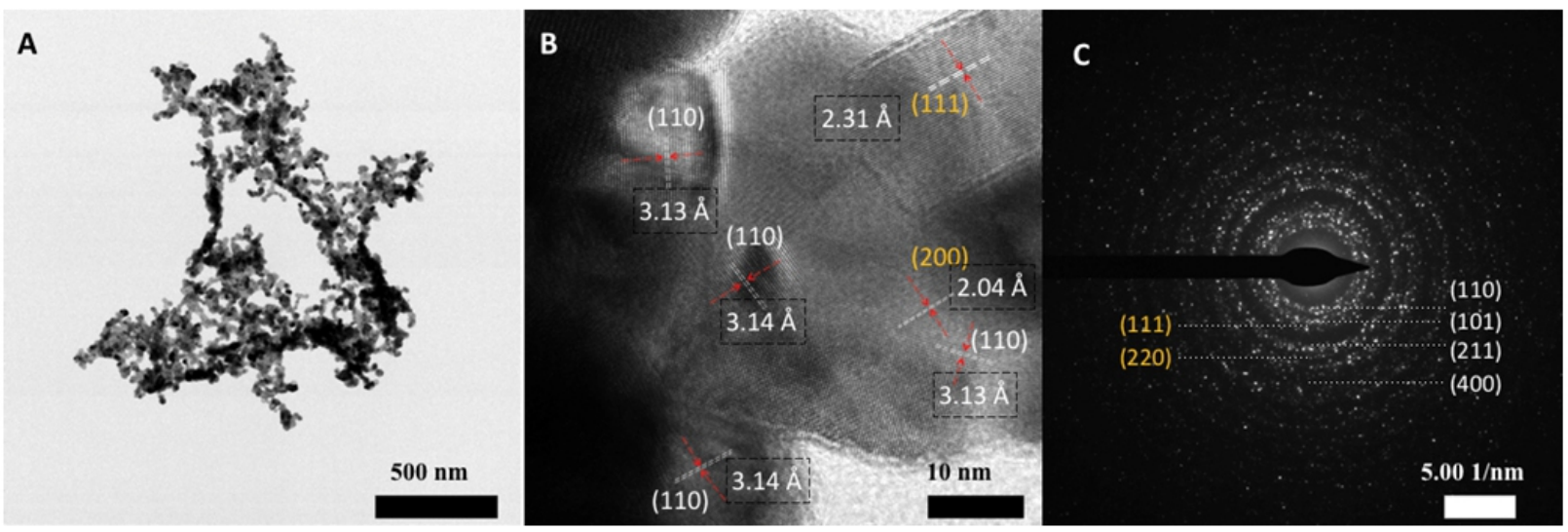

Fig. 3 (A) TEM image of $\mathrm{IrO}_{2}$-Au NCs (Scale bar $500 \mathrm{~nm}$ ). (B) HRTEM image of $\mathrm{IrO}_{2}$-Au NCs (Scale bar 10 nm). The corresponding miller indices are labeled in yellow for $\mathrm{Au}$ and white for iridium oxide. (C) The SAED pattern (Scale bar $5.001 / \mathrm{nm}$ ). 
$\mathrm{cm}^{-1}$, and $1290 \mathrm{~cm}^{-1}$ disappeared after calcination, shown in Fig. 4, indicating complete degradation of PVP.

To investigate phase purity of the as-synthesized gold-doped $\mathrm{IrO}_{2}$ nanoclusters, $\mathrm{IrO}_{2}$ nanoclusters, and gold particles, X-ray powder diffraction was applied for analysis and the results are presented in Fig. 5. The diffractions at $2 \theta=38.09^{\circ}, 44.29^{\circ}, 64.50^{\circ}, 77.49^{\circ}$ and $81.68^{\circ}$ (not shown) were measured and recorded in the calcined $\mathrm{Au}$ particles, and they were fit into the miller index of (111), (200), (220), (311), and (222) (JCPDS Card File No. 03-065-2870). The reflections at $2 \theta=27.85^{\circ}, 34.51^{\circ}, 39.80^{\circ}, 40.44^{\circ}, 53.79^{\circ}, 57.77^{\circ}, 58.21^{\circ}, 65.39^{\circ}$, $65.91^{\circ}, 69.06^{\circ}$, and $73.14^{\circ}$ were detected in the as-prepared $\mathrm{IrO}_{2} \mathrm{NCs}$. All peaks fit well with $\mathrm{IrO}_{2}$ (110), (101), (200), (111), (211), (220), (002), (310), (112), (301), and (202) (JCPDS Card File No. 15-0870), which indicate the typical cubic fluorite-like structure of $\mathrm{IrO}_{2}$. Typical Raman spectra of the as-prepared $\mathrm{IrO}_{2}-\mathrm{Au} \mathrm{NCs}$ and the precursory $\mathrm{IrCl}_{4} / \mathrm{HAuCl}_{4} / \mathrm{PVP}$ nanofibers are shown in Fig. 6. There is no obvious peak observed for precursory nanofibers. However, there are two major peaks (at 550 and $718 \mathrm{~cm}^{-1}$ ) and one minor shoulder peak (at $743 \mathrm{~cm}^{-1}$ ) for the $\mathrm{IrO}_{2}-\mathrm{Au}$ NCs. Those peaks can be assigned to $\mathrm{E}_{\mathrm{g}}, \mathrm{B}_{2 \mathrm{~g}}$ and $\mathrm{A}_{\mathrm{gg}}$ modes of the crystalline $\mathrm{IrO}_{2}$, further indicating the formation of $\mathrm{IrO}_{2}$. Moreover, no carbon trace was observed in calcined $\mathrm{IrO}_{2}-\mathrm{Au} \mathrm{NCs}$, which was corroborated by the lack of carbon's G-band at $\sim 1600 \mathrm{~cm}^{-1}$.

\subsection{Electrochemical behavior of the $\mathrm{IrO}_{2}$-Au NCs modified GCE} (Nafion//rO $\mathrm{I}_{2}$-Au NCs/GCE) toward both glucose and $\mathrm{pH}$ monitoring

\subsubsection{Glucose sensing}

Being attacked by hydroxide ions, iridium oxide has been reported to form different oxidation valences, thus endowing the electrochemical redox capability. In this study, $0.1 \mathrm{M} \mathrm{NaOH}$ and $0.01 \mathrm{M}$ PBS buffer were used as electrolytes to scrutinize the performance of the asprepared Nafion/ $/ \mathrm{IrO}_{2}-\mathrm{Au} \mathrm{NCs} / \mathrm{GCE}$ for non-enzymatic glucose sensing. The CVs (scanning from $-0.5 \mathrm{~V}$ to $+0.8 \mathrm{~V}$ vs. $\mathrm{Ag} / \mathrm{AgCl}$ ) of the Nafion/GCE (Fig. 7A) and $\mathrm{Nafion} / \mathrm{IrO}_{2}-\mathrm{Au} \mathrm{NCs} / \mathrm{GCE}$ in the absence and presence of $5 \mathrm{mM}$ and $10 \mathrm{mM}$ of glucose were first investigated in alkaline solution $(0.1 \mathrm{M} \mathrm{NaOH})$ and then $0.01 \mathrm{M}$ PBS buffer, respectively. In the absence and presence of glucose, there was no

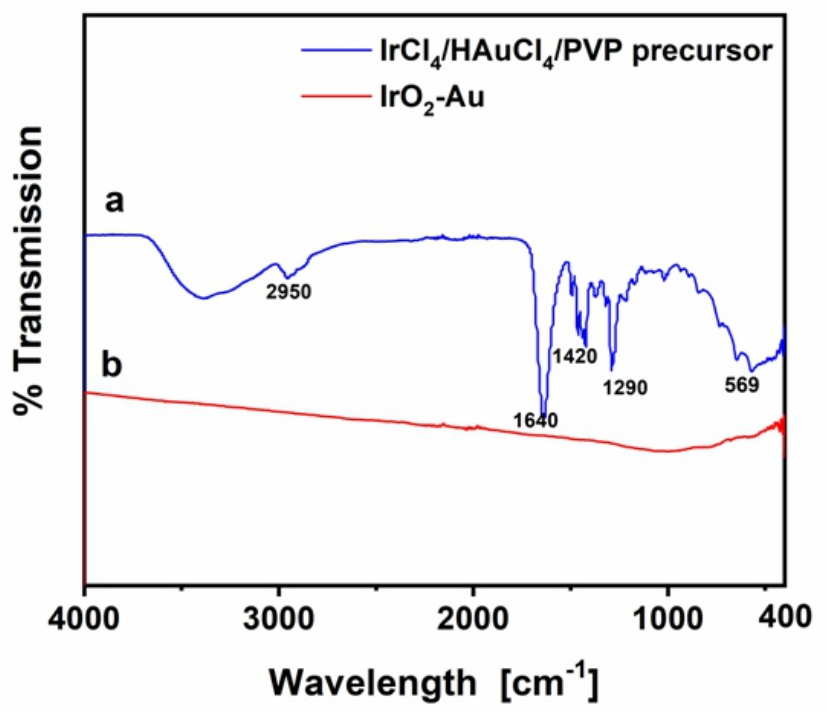

Fig. 4 The Fourier-transform infrared spectra of $\mathrm{IrCl}_{4} / \mathrm{HAuCl}_{4} / \mathrm{PVP}$ precursory nanofibers and the calcined $\mathrm{IrO}_{2}$-Au powder, respectively.

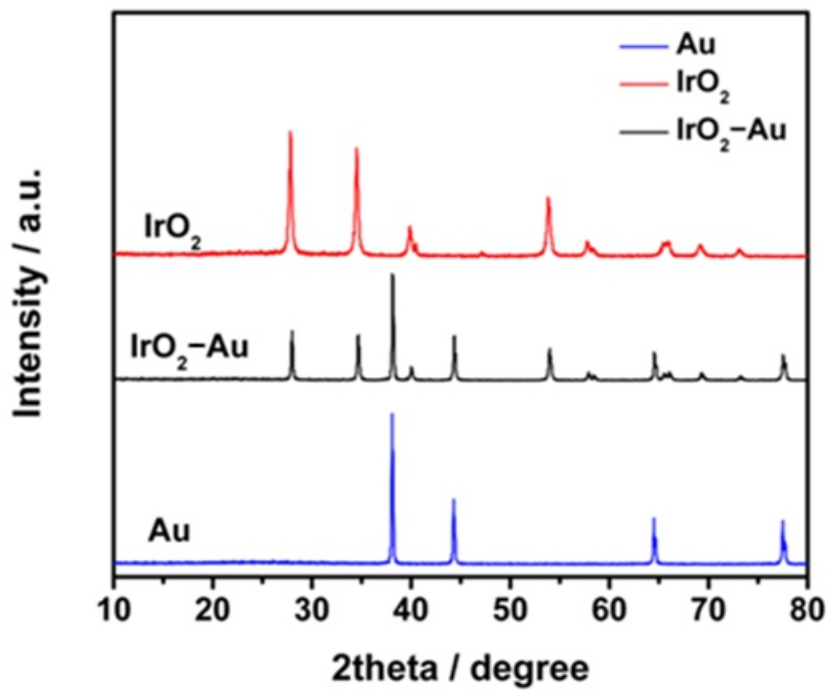

Fig. 5 The X-ray powder diffraction (XRD) analyses of Au (blue line), $\mathrm{IrO}_{2}$ (red line), and $\mathrm{IrO}_{2}-\mathrm{Au}$ (black line) from calcined $\mathrm{HAuCl}_{4} / \mathrm{PVP}$, $\mathrm{IrCl}_{4} / \mathrm{PVP}$, and $\mathrm{IrCl}_{4} / \mathrm{HAuCl}_{4} / \mathrm{PVP}$ precursory nanofibers, respectively.

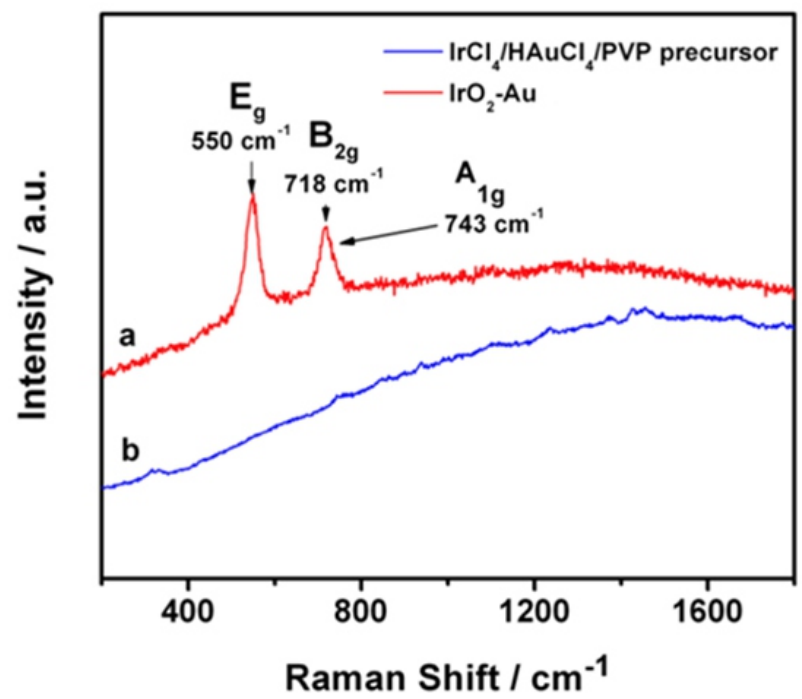

Fig. 6 The Raman spectra of calcined $\mathrm{IrO}_{2}$-Au nanoclusters (a) and precursory $\mathrm{IrCl}_{4} / \mathrm{HAuCl}_{4} / \mathrm{PVP}$ nanofibers (b), respectively. 

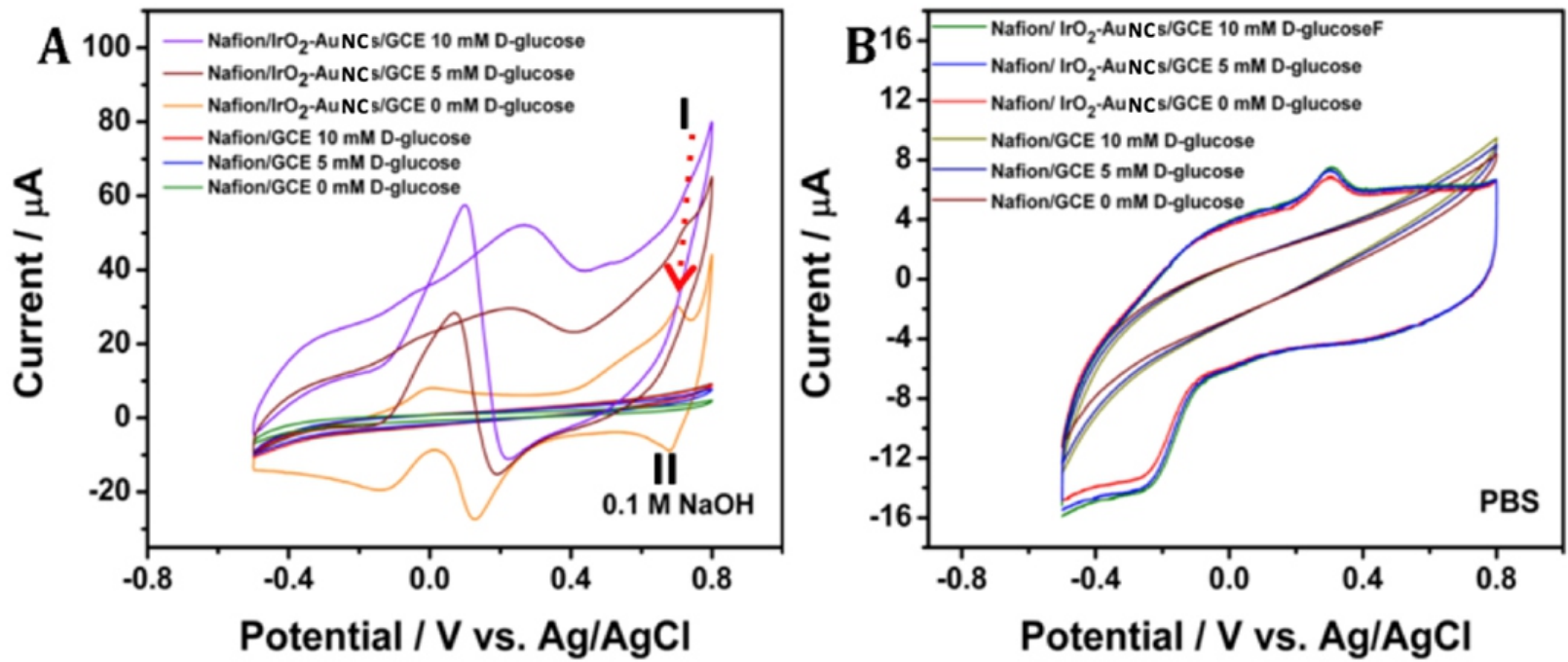

Fig. 7 (A) Cyclic voltammetry response of Nafion/GCE and Nafion/ $/ \mathrm{IO}_{2}-\mathrm{Au} \mathrm{NCs} / \mathrm{GCE}$ in the absence and presence of $5 \mathrm{mM}$ and $10 \mathrm{mM}$ glucose in $0.1 \mathrm{M} \mathrm{NaOH}$ electrolyte. (B) Cyclic voltammetry response of Nafion/GCE and $\mathrm{Nafion} / \mathrm{IrO}_{2}-\mathrm{Au} \mathrm{NCs} / \mathrm{GCE}$ in the absence and presence of $5 \mathrm{mM}$ and 10 $\mathrm{mM}$ glucose in $0.01 \mathrm{M}$ PBS buffer.
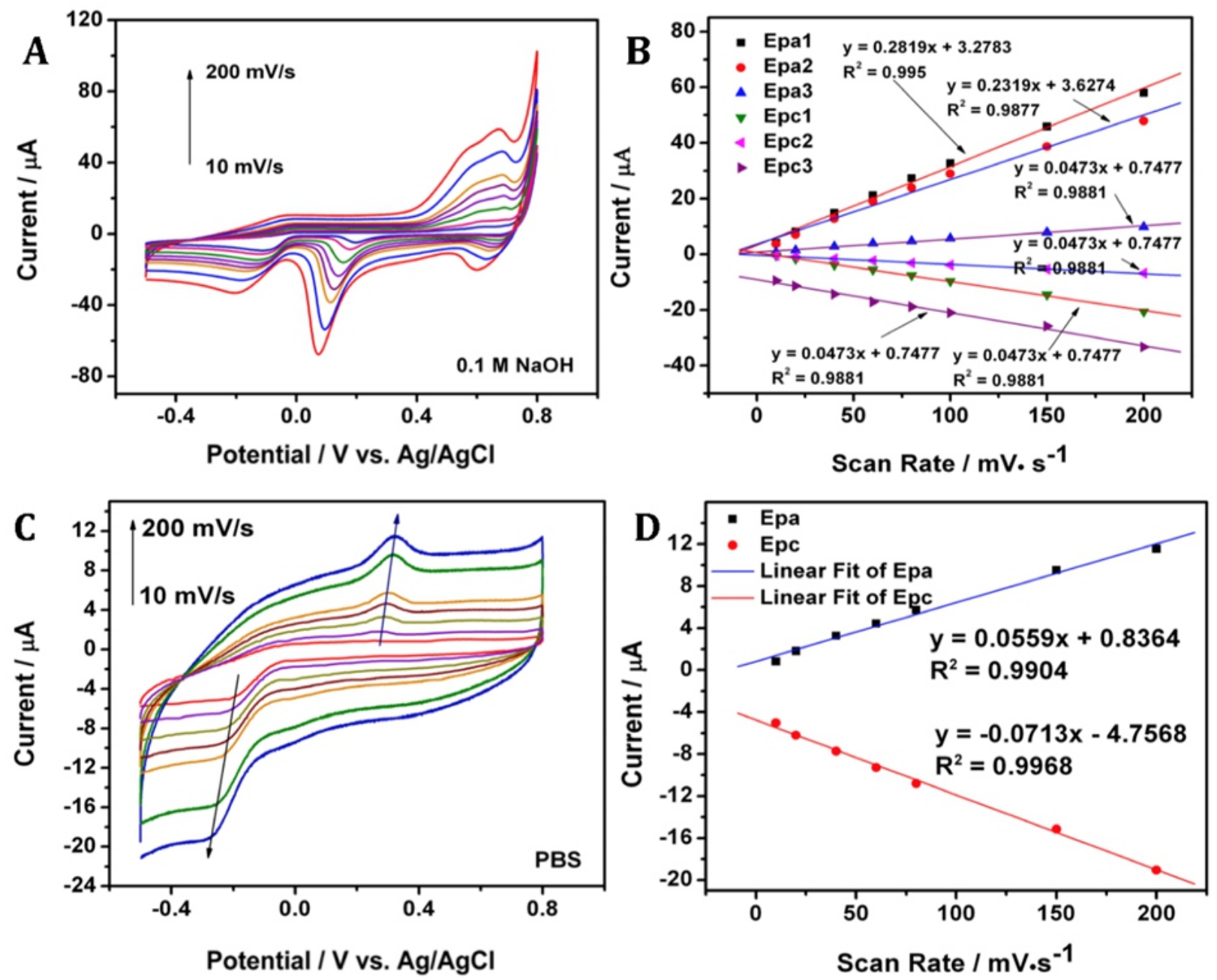

Fig. 8 Cyclic voltammetry response of Nafion/ $/ \mathrm{IO}_{2}-\mathrm{Au} \mathrm{NCs} / \mathrm{GCE}$ in the absence of glucose at different scanning rate of $10 \mathrm{mV} / \mathrm{s}, 20 \mathrm{mV} / \mathrm{s}, 40 \mathrm{mV} / \mathrm{s}, 60$ $\mathrm{mV} / \mathrm{s}, 80 \mathrm{mV} / \mathrm{s}, 100 \mathrm{mV} / \mathrm{s}, 150 \mathrm{mV} / \mathrm{s}, 200 \mathrm{mV} / \mathrm{s}$ in $0.1 \mathrm{M} \mathrm{NaOH}$ electrolyte (A) and at different scanning rate of $10 \mathrm{mV} / \mathrm{s}, 20 \mathrm{mV} / \mathrm{s}, 40 \mathrm{mV} / \mathrm{s}, 60 \mathrm{mV} / \mathrm{s}$, $80 \mathrm{mV} / \mathrm{s}, 150 \mathrm{mV} / \mathrm{s}, 200 \mathrm{mV} / \mathrm{s}$ in $0.01 \mathrm{M} \mathrm{PBS}$ buffer $(\mathrm{C})$, and their corresponding plot of peak current vs. scan rate in $0.1 \mathrm{M} \mathrm{NaOH}(\mathrm{B})$ and in $0.01 \mathrm{M}$ PBS (D). 
obvious peak observed on the Nafion/GCE, indicating negligible catalytic character towards glucose. The one for the Nafion/ $/ \mathrm{IO}_{2}-\mathrm{Au}$ $\mathrm{NCs} / \mathrm{GCE}$ shows both typical characteristic for a gold electrode (gold oxide formation and reduction) and a typical characteristic for an iridium oxide electrode (iridium oxidation (I) and reduction (II)) in the electrolyte of $0.1 \mathrm{M} \mathrm{NaOH}$. The result was in a good agreement with literature reports for gold ${ }^{21-30}$ or iridium oxide. ${ }^{17}$ Therefore, $\mathrm{IrO}_{2}-\mathrm{Au} \mathrm{NCs}$ in Nafion//rO ${ }_{2}-\mathrm{Au} \mathrm{NCs} / \mathrm{GCE}$ was responsible for the indication of glucose oxidation in alkaline environment. With the increase of glucose concentration, the peak current at ca. $+0.05 \mathrm{~V}$ increased accordingly and far more prominent than the characteristic peak of iridium oxide at ca. $+0.67 \mathrm{~V}$. Therefore, we chose to measure the glucose concentration by using the characteristic peak of gold because of its low operational potential and more pronounced response towards glucose. On the contrary, in the neutral solution of $0.01 \mathrm{M}$ PBS, the responses of both Nafion/GCE and Nafion/ $/ \mathrm{IrO}_{2}-\mathrm{Au} \mathrm{NCs} / \mathrm{GCE}$ towards the absence and presence of glucose did not display obvious difference, as shown in Fig.
7B, indicating the necessity of alkaline environment for non-enzymatic glucose oxidation. Therefore, glucose sensing was pursued only in alkaline environment.

Furthermore, Fig. 8 demonstrates the effect of the scan rate on the oxidation and reduction peak currents in the electrolyte of $0.1 \mathrm{M} \mathrm{NaOH}$ and $0.01 \mathrm{M}$ PBS buffer, respectively. One can observe that the oxidation and reduction peak current linearly increased with the scan rate from $10 \mathrm{mV} / \mathrm{s}$ to $200 \mathrm{mV} / \mathrm{s}$ (Fig. $8 \mathrm{~B}$ and 8D), indicating the typical surface-controlled electrochemical process for $\mathrm{Nafion} / \mathrm{IrO}_{2}-\mathrm{Au}$ $\mathrm{NCs} / \mathrm{GCE}$ in both electrolytes.

As the oxidation peak current of $\mathrm{Nafion} / \mathrm{IrO}_{2}-\mathrm{Au} \mathrm{NCs} / \mathrm{GCE}$ at ca. $+0.05 \mathrm{~V}$ in $0.1 \mathrm{M} \mathrm{NaOH}$ increases proportionally with glucose concentration, amperometric glucose detection using Nafion/ $/ \mathrm{IrO}_{2}-\mathrm{Au}$ $\mathrm{NCs} / \mathrm{GCE}$ was conducted at an applied potential of $+0.05 \mathrm{~V}$ (vs. $\mathrm{Ag} / \mathrm{AgCl}$ ) in the electrolyte of $0.1 \mathrm{M} \mathrm{NaOH}$. Fig. 9A shows the typical amperometric responses of the developed sensor to successive injection of glucose in $0.1 \mathrm{M} \mathrm{NaOH}$ solution. A well-defined, stable and fast
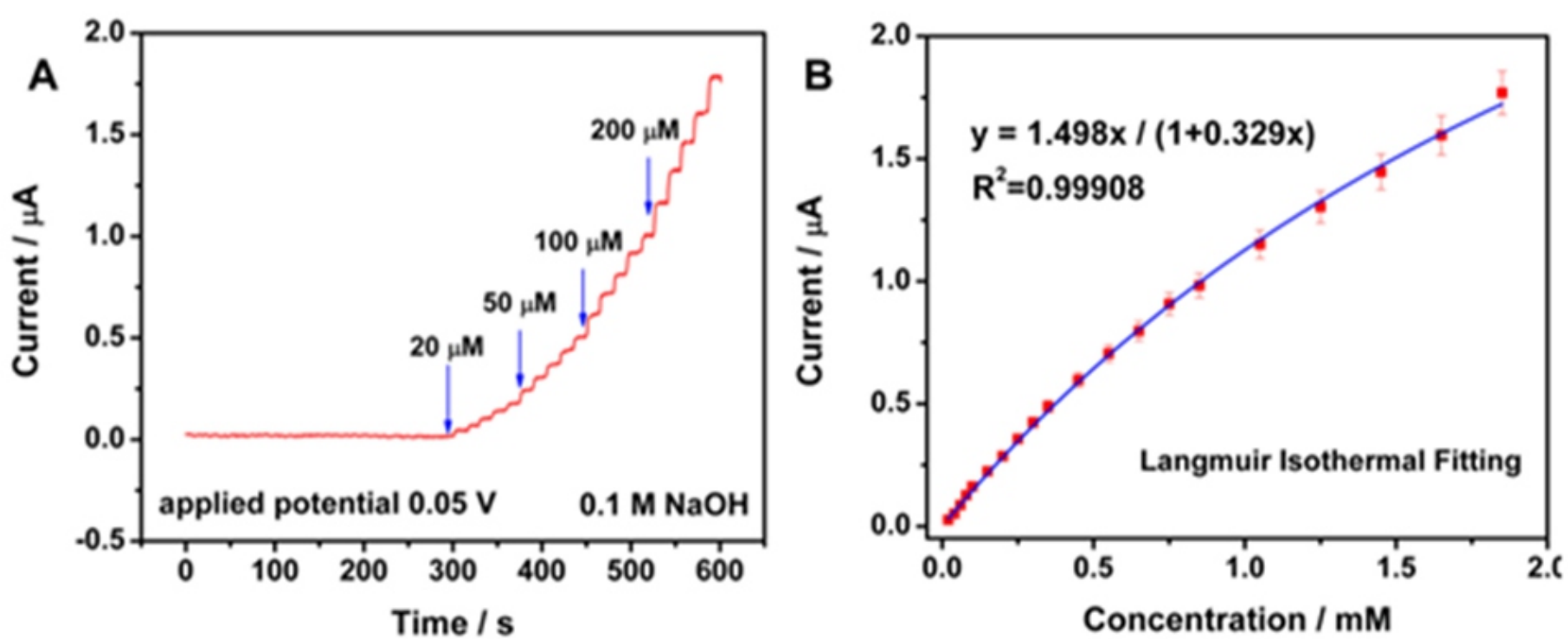

Fig. 9 Typical Amperometric response of $\mathrm{Nafion} / \mathrm{IrO}_{2}-\mathrm{Au} \mathrm{NCs} / \mathrm{GCE}$ electrode toward glucose addition in $0.1 \mathrm{M} \mathrm{NaOH}$ at $+0.05 \mathrm{~V}$ (vs. Ag/AgCl) (A) and the corresponding calibration curves (B).

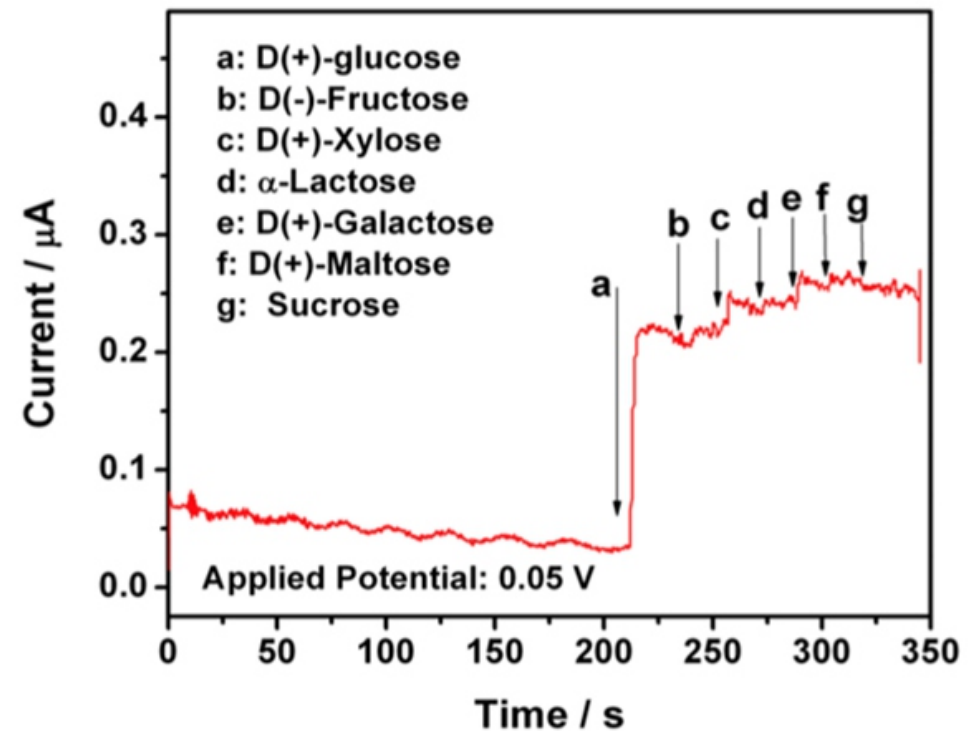

Fig. 10 Amperometric response of Nafion//rO $\mathrm{I}_{2}-\mathrm{Au} \mathrm{NCs} / \mathrm{GCE}$ towards $100 \mu \mathrm{M}$ of glucose, and $10 \mu \mathrm{M}$ of fructose, xylose, $\alpha$-lactose, galactose, maltose, and sucrose, respectively. 
amperometric response within $5 \mathrm{~s}$ can be observed on the $\mathrm{Nafion} / \mathrm{IrO}_{2}$ $\mathrm{Au} \mathrm{NCs} / \mathrm{GCE}$. With the successive addition of glucose, the Nafion//rO $\mathrm{I}_{2}$ $\mathrm{Au} \mathrm{NCs} / \mathrm{GCE}$ generated a stepwise amperometric response. The corresponding calibration curve of the current vs. glucose concentration is plotted and presented as Fig. 9B. The electrochemical oxidation of glucose on $\mathrm{IrO}_{2}-\mathrm{Au} \mathrm{NCs}$ is a surface catalytic reaction, which is typically well described by Langmuir isothermal theory in our previous study. ${ }^{8}$ Therefore, Langmuir isothermal theory was adopted to fit the calibration curve (Fig. 9B) with good fitting results (a correlation coefficient of 0.999).

$$
I(\mu A)=\frac{1.498 C_{\text {glucose }}(m M)}{1+0.329 C_{\text {glucose }}(m M)}
$$

According to the surface area of GCE, the sensitivity and the limit of detection $(\mathrm{S} / \mathrm{N}=3)$ were calculated to be $21.20 \mu \mathrm{AmM}^{-1} \mathrm{~cm}^{-2}$ and 2.93 $\mu \mathrm{M}$, respectively.

\subsubsection{Selectivity of $\mathrm{Nafion} / \mathrm{Ir} \mathrm{O}_{2}-\mathrm{Au} \mathrm{NCs} / \mathrm{GCE}$}

The selectivity of the $\mathrm{Nafion} / \mathrm{IrO}_{2}-\mathrm{Au} \mathrm{NCs} / \mathrm{GCE}$ in $0.1 \mathrm{M} \mathrm{NaOH}$ solution was also investigated against normally co-existed interfering species with glucose such as fructose, xylose, lactose, galactose, maltose, sucrose, dopamine (DA), 4-acetoamenophen (4-AP), uric acid
(UA), and ascorbic acid (AA). As the concentration of glucose in blood is typically at least 10 -fold higher than those of common interferences, ${ }^{31}$ the amperometric signal of $100 \mu \mathrm{M}$ glucose on the $\mathrm{Nafion} / \mathrm{IrO}_{2}-\mathrm{Au}$ $\mathrm{NCs} / \mathrm{GCE}$ were compared with those of $10 \mu \mathrm{M}$ fructose, xylose, lactose, galactose, maltose, sucrose, 4-AP, UA, and AA. Wang, J. et al. ${ }^{32}$ also reported the similar selectivity test for the glucose concentration towards interferences. Fig. 10 shows the current vs. time curve of the Nafion/IrO ${ }_{2}-\mathrm{Au} \mathrm{NCs} / \mathrm{GCE}$ toward the sequential injection of glucose and interfering sugars in the electrolyte of $0.1 \mathrm{M} \mathrm{NaOH}$. As shown, only xylose and galactose result in a very minor interference. In addition, the response to $10 \mu \mathrm{M} 4-\mathrm{AP}, \mathrm{UA}$, and $\mathrm{AA}$ is $3 \%, 16 \%$ and $25 \%$ of the response to $100 \mu \mathrm{M}$ glucose, respectively. This study indicates the reasonable selectivity of the developed sensor against most of co-existing interference compounds in glucose detection.

\subsection{2 $\mathrm{pH}$ sensing using the $\mathrm{Nafion} / \mathrm{IrO}_{2}-\mathrm{Au} \mathrm{NCs} / \mathrm{GCE}$}

In aqueous condition, by recording electromotive force (EMF) in varied $\mathrm{pH}$ buffer, Nernst-constant can be calculated using a calibrated curve. Since the report of both anodically oxidized iridium oxide (AOIRF) and cathodically oxidized iridium oxide (COIRF) ${ }^{33}$ iridium oxide has been extensively exploited in solid-state $\mathrm{pH}$ sensing. Typically, the redox intercalation equilibrium can be found in different oxidation states of $\mathrm{IrO}_{x}$, which is attributed to its $\mathrm{pH}$ sensing mechanism. ${ }^{34-37}$ To test the $\mathrm{pH}$
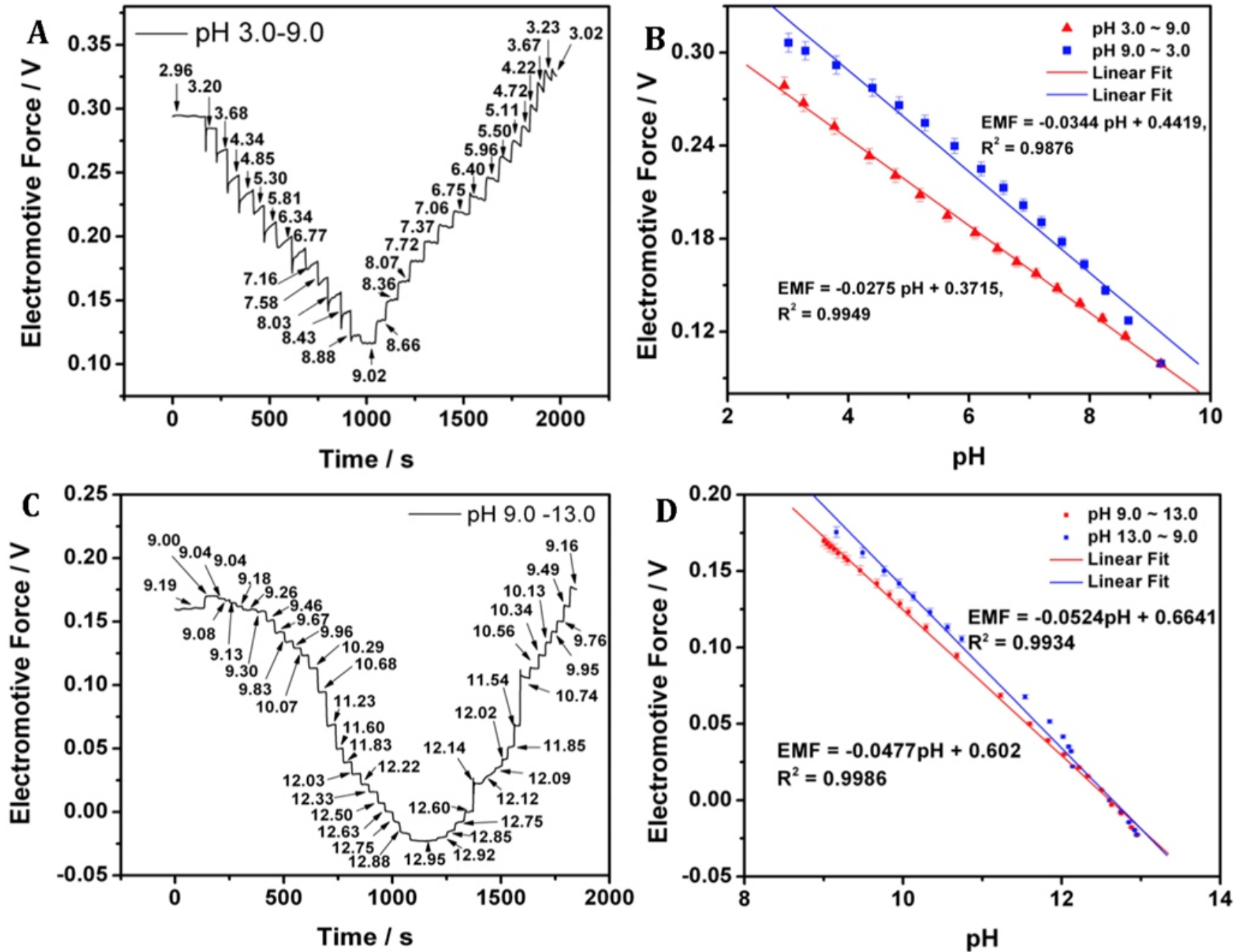

Fig. $11 \mathrm{pH}$ titration response of $\mathrm{Nafion} / \mathrm{IrO}_{2}-\mathrm{Au} \mathrm{NCs} / \mathrm{GCE}$ in the range of $\mathrm{pH} 3.0$ to 9.0 (A) and $\mathrm{pH} 9.0$ to 13.0 (C) and the corresponding EMF vs. $\mathrm{pH}$ plots (B and D). 
sensitivity of the developed $\mathrm{Nafion} / \mathrm{IrO}_{2}-\mathrm{Au} \mathrm{NCs} / \mathrm{GCE}, \mathrm{pH}$ titration experiments were conducted in different $\mathrm{pH}$ ranges. As a comparison, a commercial $\mathrm{pH}$ meter was used to record the $\mathrm{pH}$ variation in the same solution simultaneously. The corresponding EMF value was recorded in real-time format and shown in Fig. 11A and 11C. We observed that the Nafion/ $/ \mathrm{IrO}_{2}-\mathrm{Au} \mathrm{NCs} / \mathrm{GCE}$ responded to $\mathrm{pH}$ variation rapidly and the relative stable potential were typically acquired within 10 seconds, which is comparable with the stabilizing time for a commercial $\mathrm{pH}$ meter. The calculated Nernst constants are $27.50 \mathrm{mV} / \mathrm{pH}$ (titration from $\mathrm{pH} 3$ to $\mathrm{pH} 9$ ), $34.40 \mathrm{mV} / \mathrm{pH}$ (titration from $\mathrm{pH} 9$ to $\mathrm{pH} 3$ ), 47.70 $\mathrm{mV} / \mathrm{pH}$ (titration from $\mathrm{pH} 9$ to $\mathrm{pH} 13$ ) and $52.40 \mathrm{mV} / \mathrm{pH}$ (titration from $\mathrm{pH} 13$ to $\mathrm{pH}$ 9). Hysteresis was observed during titration experiment, which reflects the deviation of the open circuit potential for the same $\mathrm{pH}$ value. It could be ascribed to several factors, including different thermodynamic equilibrium formed at the same $\mathrm{pH}$ value, different hydration degree of gold-doped iridium oxide nanoclusters, etc. The slopes in Fig. 11B and D showed sub-Nernst constant at room temperature $\left(25^{\circ} \mathrm{C}\right)$ compared with the theoretical value of $59 \mathrm{mV}$. For the clarification of the Nafion membrane effect in $\mathrm{pH}$ titration experiment, Nafion/GCE was used in the same procedures. The corresponding Nernst constants are $5.8 \mathrm{mV} / \mathrm{pH}$ and $5.9 \mathrm{mV} / \mathrm{pH}$ during titration in the range of $\mathrm{pH} 3$ to 9 and $\mathrm{pH} 9$ to 3 , respectively, and negligible sensitivity towards $\mathrm{pH}$ change in $\mathrm{pH} 9$ to 13 and $\mathrm{pH} 13$ to 9 (data not shown), which indicate that the effect of Nafion on $\mathrm{pH}$ sensing of $\mathrm{Nafion} / \mathrm{IrO}_{2}$-Au NCs/GCE is minor.

\section{Conclusions}

In summary, a novel dual electrochemical sensor based on $\mathrm{IrO}_{2}-\mathrm{Au} \mathrm{NCs}$ modified glassy carbon electrode was developed. Due to $\mathrm{pH}$ sensitivity of iridium oxide and glucose oxidation capability of gold in $\mathrm{IrO}_{2}-\mathrm{Au}$ $\mathrm{NCs}$, the developed sensor was applied for both non-enzymatic glucose sensing in alkaline environment and $\mathrm{pH}$ monitoring. The results show that the $\mathrm{IrO}_{2}$ is responsible for the observed $\mathrm{pH}$ sensing capability, while $\mathrm{Au}$ is attributed to glucose detection at a low applied potential in alkaline environment. All these features indicate that the hightemperature annealed $\mathrm{IrO}_{2}-\mathrm{Au} \mathrm{NCs}$ are a promising multifunctional sensing material for the development of an integrated solid-state $\mathrm{pH}$ sensor and non-enzymatic glucose sensor.

\section{Acknowledgments}

We greatly appreciate the funding from EPA Challenging Grant and USGS. HML also thank the support from GE Fellowship. This work was supported in part by the award of a Thermo Fisher Scientific Graduate Fellowship to XW. The TEM studies were performed using the facilities in the UConn/Thermo Fisher Scientific Center for Advanced Microscopy and Materials Analysis (CAMMA).

\section{Conflict of Interest}

None.

\section{References}

1. J. C. Chou and L. P. Liao, Thin Solid Films, 2005, 476 (1), 157-161.

2. H. Chen, Y. S. Rim, I. C. Wang, C. Li, B. Zhu, M. Sun, M. S. Goorsky, X. He and Y. Yang, ACS nano, 2017, 11 (5), 4710-4718.

3. P. Batista and M. Mulato, Appl. Phys. Lett., 2005, 87 (14), 143508.
4. B. Liu, Y. Su and S. Chen, Int. J. Electron. Theor. Exp., 1989, 67 (1), 59-63.

5. W. Lv, C. H. You, S. Wu, B. Li, Z. P. Zhu, M. Wang, Q. H. Yang and F. Kang, Carbon, 2012, 50 (9), 3233-3239.

6. Y. Cheng, P. Xiong, C. S. Yun, G. Strouse, J. Zheng, R. Yang and Z. Wang, Nano lett., 2008, 8 (12), 4179-4184.

7. A. Ramsing, J. Janata, J. Růžička and M. Levy, Anal. Chim. Acta, 1980, 118 (1), 45-52.

8. Y. Ding, Y. Wang, L. Su, M. Bellagamba, H. Zhang and Y. Lei, Biosens. Bioelectron., 2010, 26 (2), 542-548.

9. C. W. Kung, C. Y. Lin, Y. H. Lai, R. Vittal and K. C. Ho, Biosens Bioelectron., 2011, 27 (1), 125-131.

10. Q. Dong, X. Wang, W. S. Willis, D. Song, Y. Huang, J. Zhao, B. Li and Y. Lei, Electroanal., 2019.

11. X. Y. Lang, H. Y. Fu, C. Hou, G. F. Han, P. Yang, Y. B. Liu and Q. Jiang, Nat. commun., 2013, 4, 2169.

12. F. Cao, S. Guo, H. Ma, D. Shan, S. Yang and J. Gong, Biosens. Bioelectron., 2011, 26 (5), 2756-2760

13. Y. Ding, Y. Liu, J. Parisi, L. Zhang and Y. Lei, Biosens. Bioelectron., 2011, 28 (1), 393-398.

14. J. Song, L. Xu, C. Zhou, R. Xing, Q. Dai, D. Liu and H. Song, ACS Appl. Materi. Int., 2013, 5 (24), 12928-12934.

15. A. Molazemhosseini, L. Magagnin, P. Vena and C. C. Liu, J. Electroanal Chem., 2017, 789, 50-57.

16. M. Long, L. Tan and A. D. Tang, Adv.Mater. Res., 2014, 3-8.

17. Q. Dong, D. Song, Y. Huang, Z. Xu, J. H. Chapman, W. S. Willis, B. Li and Y. Lei, Electrochim. Acta, 2018, 281, 117-126.

18. T. M. Cheng, T. K. Huang, H. K. Lin, S. P. Tung, Y. L. Chen, C. Y. Lee and H. T. Chiu, ACS Appl.Mater. Int., 2010, 2 (10), 2773-2780.

19. S. Park, S. Park, R. A. Jeong, H. Boo, J. Park, H. C. Kim and T. D. Chung, Biosens. Bioelectron., 2012, 31 (1), 284-291.

20. S. A. Marzouk, Analy. Chem.., 2003, 75 (6), 1258-1266.

21. G. Chang, H. Shu, K. Ji, M. Oyama, X. Liu and Y. He, Appl. Surf. Sci., 2014, 288, 524-529.

22. Y. Gu, R. Yuan, X. Yan, C. Li, W. Liu, R. Chen, L. Tang, B. Zheng, Y. Li and Z. Zhang, Analy. Chim.acta, 2015, 889, 113-122.

23. C. W. Hsu, F. C. Su, P. Y. Peng, H. T. Young, S. Liao and G. J. Wang, Sensor Actuat. B-Chem., 2016, 230, 559-565.

24. C. Li, Y. Su, X. Lv, H. Xia, H. Shi, X. Yang, J. Zhang and Y. Wang, Biosens. Bioelectron., 2012, 38 (1), 402-406.

25. A. Liu, Q. Ren, T. Xu, M. Yuan and W. Tang, Sensor. Actuat. B-Chem., 2012, $162(1), 135-142$.

26. L. Rassaei and F. Marken, Anal. Chem.., 2010, 82 (17), 7063-7067.

27. R. Sedghi and Z. Pezeshkian, Sensor. Actuat. B-Chem., 2015, 219, 119-124.

28. T. D. Thanh, J. Balamurugan, S. H. Lee, N. H. Kim and J. H. Lee, Biosens. Bioelectron., 2016, 81, 259-267.

29. C. Wang, X. G. Nie, Y. Shi, Y. Zhou, J. J. Xu, X. H. Xia and H. Y. Chen, ACS nano, 2017.

30. H. Zhu, X. Lu, M. Li, Y. Shao and Z. Zhu, Talanta, 2009, 79 (5), 1446-1453.

31. Q. Dong, Y. Huang, D. Song, H. Wu, F. Cao and Y. Lei, Biosens. Bioelectron., 2018, 112, 136-142.

32. J. Wang, L. Xu, Y. Lu, K. Sheng, W. Liu, C. Chen, Y. Li, B. Dong and H. Song, Anal. Chem., 2016, 88 (24), 12346-12353.

33. K. Yamanaka, Jap.J.Appl. Phys., 1989, 28 (4R), 632.

34. Q. Zeng, K. Xia, B. Sun, Y. Yin, T.Wu and M. S. Humayun, Electrochim. Acta, 2017, 237, 152-159.

35. J. Juodkazytė, B. Šebeka, I. Valsiunas and K. Juodkazis, Electroanal., 2005 , 17 (11), 947-952.

36. P. J. Kinlen, J. E. Heider and D. E. Hubbard, Sensor. Actuat. B-Chem., 1994 $22(1), 13-25$.

37. H. Leiva, R. Kershaw, K. Dwight and A. Wold, Mater. Res. Bull., 1982, 17 (12), 1539-1544

Publisher's Note Engineered Science Publisher remains neutral with regard to jurisdictional claims in published maps and institutional affiliations. 